\title{
Employees Knowledge sharing: A Self-Determination Viewpoint-The Case of Technology Companies in Ho Chi Minh City
}

\author{
V.V Bach ${ }^{l}$, B.Q Thong ${ }^{2}$ and P.Q Khanh ${ }^{3}$ \\ ${ }^{1}$ School of Business, International University, Ho Chi Minh, Vietnam \\ ${ }^{23}$ School of Business, International University, Ho Chi Minh, Vietnam,
}

\begin{abstract}
Self-determination theory- a new point of view of knowledge sharing dimension, is applied to explore intrinsic antecedents and to measure how influent each of them impact on knowledge sharing. A literature review suggested antecedents of knowledge sharing (Sharing intention leading to its behavior) including: altruism organizational benefit, altruism personal benefit, subjective norm and perceive competence. A survey with 396 responses is collected from people who are working in technical companies. SPSS and Analysis of Moment Structures (AMOS) are utilized to synthesis and analyze data. The results confirmed the significant relationship between altruism for personal satisfactions, perceived competence and subjective norm to knowledge sharing; whereas altruism for organizational benefit had not significant relationship to knowledge sharing Theoretical and practical implication are discussed in the context of technical companies to enhance efficiency of knowledge sharing.
\end{abstract}

Key words: Self-determination theory, knowledge, knowledge sharing, altruism for personal benefit, altruism for organizational benefit, subjective norm, perceive competence

\section{INTRODUCTION}

Today organizations try to look for one of the manner to increase their knowledge orientation in order to reach a higher level of efficiency and innovation [1]. The organizations ability in harmonizing and coordinating knowledge is one of the ways for having access and maintaining the competitive advantage in rapid changes of technology. Therefore, knowledge management is an important issue in today's organizations. One of the most important components of knowledge management is knowledge sharing. Knowledge sharing is a key factor in any organizations success since it causes the rapid development of knowledge to other sections of an organization. At present, many organizations concentrated on the fact that how knowledge and especially latent knowledge in that organizations is distributed among the organization [2]. Considering the role of tacit knowledge and the importance of using it in effective communication for better performance, one of the main factors for using the tacit and explicit knowledge of the staff for the organizational purposes is their motivation and will for cooperating in scientific relationship. Self-determination theory is accepted as a motivational theory and widely deals with the examination of the reasons for special human behaviors. Self-determination theory states that human behavior is not only due to the external and controlled motivation, but it could be recognized as due to the internal motivation and as an independent motivation. However, the fact is that most of the staffs of the organization do not have intention to share the results of their life long experiences and knowledge during low level of motivation. Therefore, it is critical to focus more on knowledge sharing due to the importance of having a knowledge based working environment

This study is formulated towards the following objectives: 1) To investigate factors affecting knowledge sharing behavior of engineering employees in Ho Chi Minh City; 2) To investigate the degree of affect that each above factor have on the knowledge sharing behavior; 3) To give 
Vo Vuong Bach/International Journal of Business and Management, 2(2) 2018, Pages: 30-39

recommendation to technology companies in Ho Chi Minh City to improve the employees' knowledge sharing behavior.

\section{LITERATURE REVIEWS}

\section{Knowledge \& Knowledge Sharing}

\section{Knowledge}

In 2010, Daghfous and Ahmad idenfied knowledge as "a state of knowing that constitutes facts, concepts, principles, laws, causal relationships, insights, judgments, intuitions, and feelings" [3]. Basically, there are two types of knowledge: explicit and tacit forms. The term "tacit knowledge" was firstly introduced by Polanyi in 1966 [4]. A huge amount of human knowledge is hard to be expressed in words since it can only be gained through individual experience [5]. Thus, without the experienced person, this tacit knowledge cannot be easily used or expressed as the explicit form. In contrast, explicit knowledge can be easily expressed, stored or transferred all over the world without the experienced person [6]. Even each individual has a limited amount of knowledge within the organization, he or she does strongly contribute to the knowledge management of the organization.

\section{Knowledge Sharing}

Knowledge sharing is the main factor of the knowledge management system within an organization. However, there is no unique perspective of "knowledge sharing". For example, Lee and Al-Hawamdeh, in a research conducted in 2002 [7], concluded that knowledge sharing is a "deliberate act that allows knowledge to be reuse by other people through knowledge transfer." Lately, Boon-In, Choy-Har, Chee-Hoong, Keng-Boon, and Felix in 2010 [8] added in that knowledge sharing is any activities to extent the knowledge of each individual to others, or a process of transforming knowledge from tacit form to explicit form. Each individual has specific viewpoints and knowledge within an organization. Therefore, the interactions between them could lead to positively affect individuals in innovative activities, hence increasing the knowledge ability of the organization.

Individuals must overcome many barriers to share their knowledge. The implicit knowledge is within individual experience, such as invisible information, skills or ideas. Therefore, it is hardly articulated in words to communicate or share between individuals. In contrast, the explicit knowledge is easily expressed in words. It could be shared with ruled and systems under the form of data, formula or procedure [9]. The other barrier comes from the perception of an individual who owns the knowledge. He or she refuses to share the knowledge because the fear of losing the superiority or not rewarded adequately or even time and resource lacking [10]. In addition, the poor knowledge sharing environment is also an enormous barrier. Therefore, the organization has to understand how to create an effective interaction between individuals to motivate the sharing knowledge behaviors of their employees.

\section{Theory of Self-Determination \& its point of view on Knowledge Sharing Behavior}

\section{Theory of Self-Determination}

The nature of self-determination theory is that human behavior can be motivated by the interaction between the extrinsic factors (controlled motivation, i.e., rewards, grades or evaluations) and the intrinsic factors (autonomous motivation, interests). Autonomous motivation is the motivation welldefined as individuals who autonomously act certain behaviors without any external rewards or selfbenefits. They internally feel self-motivated when perform these certain behaviors based on their own "interests, curiosity, care or abiding values". The controlled motivation, in contrast, is motivations in which individuals, based on self-benefits and selfneeds, perform certain behaviors. Usually, there are external pressures or requirements on individuals to reach an essential outcome. The external motivations including "reward systems, grades, evaluations, or the opinions they fear others might have of them." All these external factors make individuals feeling being controlled when performing certain behaviors.

Previous studies show that there are four principles of self-determination theory. Firstly, selfdetermination theory clearly states that autonomous motivations are different compared to controlled motivations [11-13]. Therefore, every behavior, depended on the level of being induced by autonomous or controlled motivations, can be classified into self-determined or non-selfdetermined. The second premise refers to the quality of the autonomous/controlled motivation determined by how good individuals satisfied with the psychological needs for autonomy, competence and relatedness when performing a certain behavior. It seems that controlled motivations seem to have 
Vo Vuong Bach/International Journal of Business and Management, 2(2) 2018, Pages: 30-39

less positive result than autonomy motivations in different situations. The reason is that performing a sharing action under autonomy-oriented motivations make individuals feels more certainly satisfied with the three human psychological needs. In contrast, controlled-oriented motivations bring more pressure by external forces/incentives [14]. As a result, to increase the quality of motivating individuals' behaviors, it is better to make it more autonomyoriented. Thirdly, individuals' behavior may be interfered by the interaction between autonomy and controlled motivations. Particularly, depending on the way that satisfies the above discussed psychological needs, autonomy motivations may strengthen or undermine controlled motivations and vice versa.

The remaining principle of self-determined theory is "the proposition of a controlled-toautonomous continuum". This continuum describes the levels of motivations to perform a certain behavior, from the fully controlled motivation (created and kept by external factors, such as rewards/benefits for individuals) to the fully autonomous motivation (which is done by selfinterest, without external rewards/benefits). Based on this continuum, three main categories are divided among motivations [15]. Firstly, motivation describes the lack of motivation context when there is no regulation or reward. The second category named extrinsic motivation, which is then divided into four sub-categories. The first sub-category is the controlled motivation regarding the context when individuals' behavior is fully controlled and pressured by external regulation. Secondly, the moderately controlled motivation is when individuals still perform the behavior under external controls and pressures, even when the value of the behavior is not truly known (e.g. introjected regulation). The next sub-category is the moderately autonomous motivation, which means that there is more freedom when individuals perform the specific behavior because they understand its value and are willing to accept responsibility. The autonomous motivation is the last sub-category of extrinsic motivation. The regulation is seemed to be truly autonomous and makes the behavior translational moving to reach the individuals' values and goals. Finally, intrinsic motivation can be explained as autonomous motivation. Individuals autonomously engage to a specific behavior because they feel interested and enjoyable.

\section{A Self-determination viewpoint on Knowledge Sharing behaviors of employees}

Literature review shows that a connection between the motivation and individuals' expectations is essential to make individuals engaging in a certain behavior $[12,16]$. According to self-determination theory, previous knowledge sharing studies were mostly indicated the motivations related to external forces/regulations (e.g. rewards, grades or evaluations). This statement means that autonomy-oriented motivation concept in knowledge sharing studies is either unnoticed or wrongly combined into the controlled-oriented motivation concept.

In reference of self-determination theory, prior studies on knowledge sharing behaviors have scanned through different motivational factors in order to understand and explain knowledge sharing behaviors. However, the difference between these motivation factors is still suspicious and inconsistent. In addition, none of these studies has accepted all the four motivation types of selfdetermination theory at the same time. Furthermore, a number of studies that adopt self-determination theory concluded that controlled motivation is not as much important as autonomous motivation when linked to knowledge sharing behaviors [11, 17-18]. Therefore, this study will only concentrate on autonomous motivations in SDT and conclude the quality of motivations presented in selfdetermination theory.

\section{Altruism factor as Automony-oriented motivations:}

In the case of understanding knowledge sharing behaviors associated with autonomy-oriented motivations in self-determination theory, soft and hard rewards have limited influences. The reason behinds this phenomenon is that prior studies were mistaken or wrongly assigned the concept of autonomous motivations to parts of intrinsic rewards even if they are worthy to be considered individually. In addition, prior studies [19-20] agree that knowledge sharing behaviors are motivated by both expectations of individuals' benefits and of third parties' benefits (e.g., communities or organization). These "selfless knowledge sharing behaviors" are equivalent to the altruism concept [21].

The altruism concepts for benefits of both organization and personal satisfaction are recognized and implemented in this study in order to symbolize the concept of autonomous motivation in 
Vo Vuong Bach/International Journal of Business and Management, 2(2) 2018, Pages: 30-39

self-determination theory. First, Chiu et al. [22] defined altruism for organization benefits as the evaluations of individuals' positive influence regarding the knowledge sharing behaviors in their organizations. This is reflected as one type of moderately autonomous motivations. In the other hand, personal satisfaction altruism is defined by Hall [23] as persons may feel enjoyment about the optimistic results regarding their knowledge sharing behaviors. Thus, it is identified as a form of autonomous motivations. Prior studies indicate that there is only one different between these two altruisms, which is intrinsic motivations defined as the overall expression of motivational factors which are approaching closer to autonomy-oriented motivations.

The main reason causes individuals to perform a specific behavior while this does not bring any selfbenefit to them is that this behavior may bring significant benefits to his/her external entities (i.e., organization) [24]. Sharing the same idea, Bock and Kim [25] pointed out that the degree of employees' competence is positively developed related to the knowledge sharing behaviors of employees, which is not depended on the external rewards (e.g., hard and soft rewards). Additionally, some of the benefits related to altruism for organizational benefits are the decrement of unnecessary interpersonal competition and the increment of collaboration which then lead to employees' positive relationships and employees' self-improvement perspectives [26]. Employees who receive feedbacks from the previous knowledge sharing activities may have a deeper understanding on how they can positively help the work of others or even the performance of the organizational. Thus, employees' sense of self-worth is initiated and sustained [27]. Consequently, they will positively keep their knowledge sharing activities.

Prior studies argue that the satisfied and pleased feeling of the positive outcomes of helping others leads to employees' knowledge sharing behaviors [28-30]. In addition, when joining to virtual communities, humans tend to share common goals or desires. Thus, their altruistic intention to perform knowledge sharing behaviors are increasing because of the pleased feeling of helping others in the firm (i.e., personal satisfaction related altruism) and viewing the community's achievements of those sharing goals or desires (i.e., organizational benefits related altruism). This results in the below hypotheses.
H1: Altruism which is related to organizational benefits influences individuals' intention to share knowledge.

H2: Altruism which is related to personal satisfaction influences individuals' intention to share knowledge.

Subjective Norm and its impacts on Knowledge Sharing: Prior studies about the knowledge sharing behaviors based on SDT were mostly concerning about the reward factors and the personal factors of the person who performs the knowledge sharing. In order to make the research cover a wider approach, the factors of subjective norm were taken from the theory of planned behaviors. Subjective norm is an individual's perception about the particular behavior, which is influenced by the judgment of significant others (e.g., parents, spouse, friends, teachers). In the context of this research, leadership and organizational culture are considers as the subjective norm factors that affect to the employee knowledge sharing behaviors.

According to the TPB model, normative beliefs usually bring on subjective norm which relates to the view of individuals being accustomed by other colleagues to exhibit an attention manner. Various studies have uncovered that along with following up settlement rules, job evaluation and development, they start to proceed activities on knowledge management. Consequently, subordinate colleagues tend to involve in knowledge sharing activities in order to fulfill the expectations of their managers. Subjective standard has been observed to be a fundamental essential to behavioral expectation. As a result, the normative beliefs of workers about the desires of the managers and the expert team beneficially affect their knowledge sharing intention.

In a study conducted by Srivastava, Locke and Bartol [31], they emphasized that in the beginning, within a team, knowledge sharing is not occurred automatically. This activity is only encouraged and nurtured by the team leader. Thus, he plays a significant part of knowledge sharing activities.

Organizational culture play an important role in the success of knowledge sharing in one organization. It is also a contributing element to the beliefs and behaviors of each members in that organization. According to McDermott and O'Dell [32], individuals' actions and expectations are greatly related to the value of culture of the collective unit. Therefore, individuals tend to perform knowledge sharing activities based on the 
Vo Vuong Bach/International Journal of Business and Management, 2(2) 2018, Pages: 30-39

core values of organization. In conclusion, when working in an organization where knowledge sharing has been already a culture, individuals tends to share about their experiences and knowledge more than when they are in a non-established knowledge sharing culture organization. In conclusion, a hypothesis related to subjective norm is formed:

H3: A high level of subjective norm that supports knowledge sharing leads to the intention to share knowledge.

Perceive competence and its impacts on knowledge sharing behaviors: Human do not simply act, they likely mirror their perception through their actions. A part of these perceptions is about the concerns of their own competence and capacities when performing a specific activity. According to the self-concept theory, perceived competence includes the "perception and evaluation" about the skills in various fields of individuals. When interacting with the environment, perceived competence takes an important position when showing individuals' possibilities to complete specific tasks or activities. Perceived competence is not a whole consistent build, but rather is partitioned in particular perceived competences for various skills and fields. A global competence is portrayed as a general perception of one's own skill to adapt to various parts of life. However, this does not mean that the sum of various field perceived competences is equal the global competences. The global competence is contributed differently depends on the influence of each particular perceived competence and depends on the significance of the particular skill for the environment and for the individual. In addition, Harter said that the accuracy of the perceived competence also impacts to the global perceived competence.

Bandura [33] stated that perceived competence is dictated by two procedures: first the choice and second the information handling. This information may comprise of one's own past accomplishments, attributes of the works performed, information about exhibitions of others and the qualities of these others and the responses of others to achievements and failures. The information is chosen and used differently to accomplish a perceived competence. The distinctions rely on individual thoughts and hypotheses about what causes one's accomplishments [34]. These individual hypotheses are impacted by experience in the past with accomplishment results and by information from others. Individuals tend to assets in a manner that their perceived competence is acknowledged [35]. Therefore, it exists a round impact between thoughts regarding one's own ability and attributions.

Evidently, individuals have a sort of perception or hypothesis of their capability and use rules for choosing and handling information about their own particular capability in a manner that this hypothesis or perception is affirmed. Ideally, the development of perceived competence requires a complex intellectual procedure. However, it shows up that individuals generally utilize just a little of their own information and use basic guidelines which are not generally discerning. In conclusion, the perceived competence of an individual is dictated by the information that is accessible and by the individual style of choosing and preparing this data. As a result, a hypothesis is created as.

\section{H4: Perceived competence impacts on the intention to share knowledge \\ Knowledge sharing behaviors in reality} actions: The knowledge sharing behavior of knowledge employees is determined by their intention to share their knowledge and their PBC. Knowledge sharing behavior refers to the extent to which knowledge employees share their knowledge with their fellow colleagues. Intention determines the willingness of an individual to engage in knowledge sharing. In general, a positive intention equates with a high knowledge sharing tendency. Thus, we propose the following hypothesis.

H5: A high level of intention toward knowledge sharing leads to great knowledge sharing behaviors.

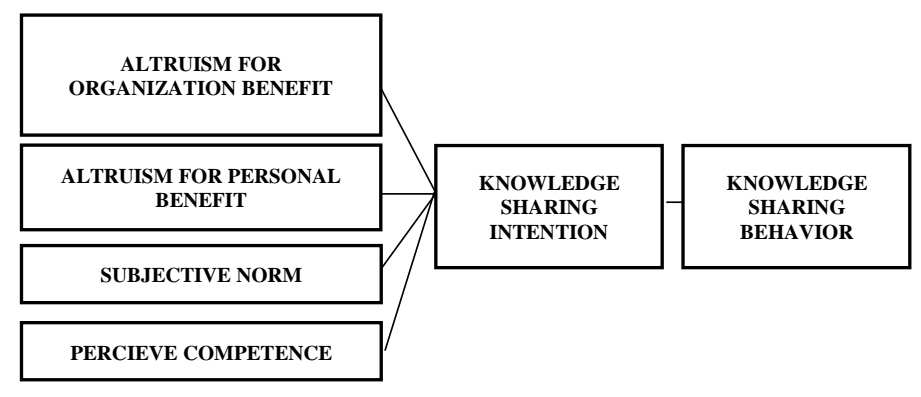

\section{METHODOLOGY}

\section{Questionnaire Design and Data Collection}

Based on the research objectives, quantitative approach is conducted to collect data and explore research finding. The effects of employees' knowledge sharing behavior and its antecedents are 
Vo Vuong Bach/International Journal of Business and Management, 2(2) 2018, Pages: 30-39

explored by numerical data through survey evaluation. Target population of this research is employees working in technical companies in Ho Chi Minh City. In detail, they may work in departments of hardware office, software office, factory engineer, sale \& customer service office, from low position of junior staff to front-line or middle management. The number of needed sample size is calculated following the formula $(\mathrm{n}=50+8 \times \mathrm{m})$ where $\mathrm{m}$ is number of independent variables. However, the questionnaires were conveniently delivered to respondents for more significant research results as well as Amos data analysis. The research need a larger sample size to cover the significance and suggest realistic recommendation. Therefore, a mixture of nearly 400 direct and online structured questionnaires are delivered to respondents who work in technical companies in Ho Chi Minh City. After eliminating numbers of questionnaires which was uncompleted or not satisfied conditions of the research, 384 fully done survey were accepted to utilize for deep-diving in analysis.

Questionnaire design: In a questionnaire, measurement scale is considered as a critical issue to consider as it directly impacts to the final result. In general, measurement scale is divided into three different groups: nominal, ordinal and interval/ratio [36-38]. In this research, interval scales are mainly used because of its optimal characteristic in multivariate statistical techniques [37-39]. Besides, nominal scale is used in general questions, such as gender, age and occupation. In addition, Likert scale is also applied in this research [40]. According to Ghiselli [41] and Guilford [42], size of scale should be developed based on the circumstances. The scale must not be too large which is hard for all respondents to identify their answers. Also, the scale must not be too small otherwise it is very hard to distinguish among answers. As a result, a scale of five points is applied in conducted survey. Most of statements with five-point Likert scale which are equivalent to " $1=$ strongly disagree", " $2=$ disagree", " 3 = neutral", " 4 = agree", and " $5=$ strongly agree". Coding and analyzing: data collected from the target respondent were analyzed by SPSS version 20.0 to synthetic and evaluate statistics. For the purpose of running SPSS, the variables knowledge sharing behavior, knowledge sharing intention, altruism for organization benefit, altruism for personal benefit, subjective norm, perceive competence are coded as followings respectively: KNOSHABEHA,

\section{KNOSHAINT, ALORGBEN, ALPERBEN, SUBBORM and PERCOMP.}

\section{Reliability and factor analysis}

The table I summarizes the dependent \& independent variables, reliability index. With Cronbach's Alpha of all variables greater than 0.794 , stands in, this was considered to be a good reliable measurement. In addition, the KMO equaled to 0.911 proved that factor analysis is appropriate with the data. As the Sig. of Balett's test equaled to 0.0 , so the null hypothesis that the observation items are not correlated within the factor is rejected. On the other word, this claimed that the data used into analysis were totally suitable, the test was statistically significant.

TABLE I: SUMMARY OF THE INDEPENDENT \& DEPENDENT VARIABLES

\begin{tabular}{ccc}
\hline Given names & $\begin{array}{c}\text { Number } \\
\text { of items }\end{array}$ & $\begin{array}{c}\text { Cronbach's } \\
\text { Alpha }\end{array}$ \\
\hline KNOSHABEHA & $2 *$ & .862 \\
\hline KNOSHAINT & $4^{*}$ & .919 \\
\hline ALORGBEN & $3 *$ & .888 \\
\hline ALPERBEN & $3 *$ & .898 \\
\hline SUBBORM & $4 *$ & .794 \\
\hline PERCOMP & $4 *$ & .921 \\
\hline $\begin{array}{l}* \text { All items have factor loadings } \geq 0.5 \\
\text { KMO index }=.911 \text { and Sig. of Bartlett's test }=.000\end{array}$ \\
Total variance explained = 70.83\%
\end{tabular}

As demonstrated in table I, five out of six factors of dependent and independent variables had Cronbach's Alpha index in the interval [0.794; 0.921], meaning that these factors had good reliable measurement. However, Factor loading of knowledge sharing behavior has been removed two items. Moreover, these figures are even greater than 0.600. Thus, the internal consistency within this factor could be considered acceptable. The KMO was at 0.911 also meant that factor analysis is appropriate with the data .The Sig. of Bartlett's test was at $.000<.05$ referring that the data of independent variables was appropriate for factor analysis. Thus, the data can be then used for exploratory factor analysis (EFA)

Output from EFA analysis after eliminating some useless items were presented on Table III. The KMO index $=0.911$ and Bartlett's test $=0.00$ showed above provided enough condition for EFA. Items were loaded neither at the same time on many factors nor lower than 0.5 . These totally met conditions of convergent validity and discriminant validity. Six factors were extracted which had proper observing variables with literature. These factors were then remained their variable names as no new factor was extracted from EFA running. 
TABLE II: COMPONENT MATRIX

\begin{tabular}{|c|c|c|c|c|c|c|}
\hline & \multicolumn{6}{|c|}{ Component } \\
\hline & $\overline{1}$ & 2 & 3 & 4 & 5 & 6 \\
\hline PERCOM1 & .791 & & & & & \\
\hline PERCOM2 & .716 & & & & & \\
\hline PERCOM3 & .690 & & & & & \\
\hline PERCOM4 & .671 & & & & & \\
\hline KNOSHAINT1 & & .852 & & & & \\
\hline KNOSHAINT1 & & .816 & & & & \\
\hline KNOSHAINT1 & & .803 & & & & \\
\hline KNOSHAINT1 & & & .896 & & & \\
\hline SUBNORMS1 & & & .835 & & & \\
\hline SUBNORMS2 & & & .798 & & & \\
\hline SUBNORMS3 & & & & .765 & & \\
\hline SUBNORMS4 & & & & .755 & & \\
\hline ALPERBEN1 & & & & .707 & & \\
\hline ALPERBEN2 & & & & .580 & & \\
\hline ALPERBEN3 & & & & & .778 & \\
\hline ALORGBEN1 & & & & & .756 & \\
\hline ALORGBEN2 & & & & & .622 & \\
\hline ALORGBEN3 & & & & & .578 & \\
\hline KNOSHABEHA & & & & & & .827 \\
\hline KNOSHABEHA & & & & & & .792 \\
\hline $\begin{array}{l}\text { Extraction Metho } \\
\text { Rotation Method: }\end{array}$ & $\begin{array}{l}\mathrm{d} \text { : Prin } \\
\text { Proma }\end{array}$ & $\begin{array}{l}\text { al Cor } \\
\text { with K }\end{array}$ & $\begin{array}{l}\text { ponent } \\
\text { tiser } \mathrm{Nc}\end{array}$ & $\begin{array}{l}\text { Analy } \\
\text { rmaliz }\end{array}$ & $\begin{array}{l}\text { is. } \\
\text { tion. }\end{array}$ & \\
\hline
\end{tabular}

\section{RESEARCH FINDINGS}

\section{A. Sample description}

TABLE III: RESPONDENTS' PROFILE

\begin{tabular}{|c|c|c|c|}
\hline & & Frequency & Percent \\
\hline \multirow{3}{*}{$\begin{array}{l}\text { Job } \\
\text { position }\end{array}$} & Staff & 273 & 82.7 \\
\hline & First-line Manager & 31 & 9.4 \\
\hline & Middle Manager & 26 & 7.9 \\
\hline \multirow{2}{*}{ Gender } & Male & 198 & 50.0 \\
\hline & Female & 198 & 50.0 \\
\hline \multirow{4}{*}{ Age } & $<18$ & 0 & 0 \\
\hline & $18-30$ & 350 & 88.39 \\
\hline & $30-40$ & 42 & 10.6 \\
\hline & $>40$ & 4 & 0.01 \\
\hline \multirow{8}{*}{ Occupation } & Factory Engineer & 6 & 1.52 \\
\hline & Software Engineer & 100 & 25.25 \\
\hline & Hardware Engineer & 21 & 5.32 \\
\hline & Officer & 125 & 31.56 \\
\hline & IT Officer & 19 & 4.79 \\
\hline & Sales & 20 & 5.05 \\
\hline & Customer Services & 27 & 6.82 \\
\hline & Others & 78 & 19.69 \\
\hline \multirow{5}{*}{ Education } & High school & 1 & 0.25 \\
\hline & Undergraduate & 314 & 79.29 \\
\hline & Master & 75 & 18.96 \\
\hline & Postgraduate & 3 & 0.75 \\
\hline & Others & 3 & 0.75 \\
\hline
\end{tabular}

Table III represented the demographic profiles of the respondents. By can be seen, all of participants in this research were working at the technical companies with diversified occupation and job position. The respondents have bachelor/ undergraduate that dominated the total, accounted for nearly 79.29 per cent. Not many people from middle age worked in these companies because almost of them are young employees aged from 18 to $30(88.39$ per cent $)$.

B. Confirmation factor analysis (CFA) \& validity testing between all variables

\section{Model Fit Testing}

The first step is using CFA to test if the research framework and collected data are in solid match. The below table matches the result of suggested factors for fit indices and the current research fit indices.

\begin{tabular}{lcc}
$\begin{array}{c}\text { Fit } \\
\text { Indices }\end{array}$ & $\begin{array}{c}\text { TABLE IV: MODEL FIT OF CFA } \\
\text { Recommended } \\
\text { value }\end{array}$ & $\begin{array}{c}\text { Current fit } \\
\text { indices }\end{array}$ \\
\hline CMIN/DF & $<0.5$ & 2.344 \\
\hline GFI & $>0.9$ & 0.913 \\
\hline CFI & $>0.9$ & 0.962 \\
\hline TLI & $>0.9$ & 0.954 \\
\hline RMSEA & $<0.06:$ good fit & 0.059 \\
\hline
\end{tabular}

All the indices stay in the recommended value range. Therefore, this measurement shows the good fit of research model.

\section{Convergent Validity}

The convergent validity is achieved if factor loading for each item greater than or equal 0.5 and Average Variance extracted (AVE) greater than 0.5. Firstly, all factors loading are ranging from 0.500 to 0.851 (Table 5). The lowest AVE is subjective norms (0.500, respectively) and the highest AVE is knowledge sharing behavior (0.767). Other AVEs are greater than 0.5 . These figures suggest a good convergent validity.

TABLE V: CONVERGENT VALIDITY

\begin{tabular}{|c|c|c|c|c|}
\hline Items & CR & AVE & MSV & $\operatorname{MaxR(H)}$ \\
\hline ALORGBEN & 0.888 & 0.726 & 0.321 & 0.890 \\
\hline PERCOMP & 0.923 & 0.750 & 0.334 & 0.955 \\
\hline KNOWSHAINT & 0.923 & 0.750 & 0.508 & 0.973 \\
\hline SUBNORMS & 0.797 & 0.500 & 0.392 & 0.976 \\
\hline ALPERBEN & 0.901 & 0.751 & 0.508 & 0.981 \\
\hline KNOSHABEHA & 0.868 & 0.767 & 0.373 & 0.984 \\
\hline
\end{tabular}

\section{Discriminant Validity}

The discrimination validity of each construct can be measured through the following indices and thresholds:

- $\quad$ AVE $>r 2$

- $\quad$ Maximum Shared Variance $(\mathrm{MSV})<\mathrm{AVE}$

- $\quad$ Average Shared Variance (ASV) $<$ AVE

The below results reflect that all criteria are met. 
Vo Vuong Bach/International Journal of Business and Management, 2(2) 2018, Pages: 30-39

Therefore, the discrimination is achieved.

TABLE V: DISCRIMINANT VALIDITY

\begin{tabular}{|c|c|c|c|c|c|c|}
\hline & $\begin{array}{l}\text { ALOR } \\
\text { GBEN }\end{array}$ & $\begin{array}{c}\text { PERC } \\
\text { OMP }\end{array}$ & $\begin{array}{c}\text { KNOW } \\
\text { SHAIN } \\
\mathrm{T}\end{array}$ & $\begin{array}{l}\text { SUBN } \\
\text { ORMS }\end{array}$ & $\begin{array}{l}\text { ALPE } \\
\text { RBEN }\end{array}$ & $\begin{array}{l}\text { KNOSH } \\
\text { ABEHA }\end{array}$ \\
\hline $\begin{array}{l}\text { ALORG } \\
\text { BEN }\end{array}$ & 0.852 & & & & & \\
\hline $\begin{array}{c}\text { PERCO } \\
\text { MP }\end{array}$ & 0.486 & 0.866 & & & & \\
\hline $\begin{array}{c}\text { KNOWS } \\
\text { HAINT }\end{array}$ & 0.567 & 0.578 & 0.866 & & & \\
\hline $\begin{array}{c}\text { SUBNO } \\
\text { RMS }\end{array}$ & 0.452 & 0.330 & 0.626 & 0.707 & & \\
\hline $\begin{array}{c}\text { ALPER } \\
\text { BEN }\end{array}$ & 0.564 & 0.440 & 0.713 & 0.522 & 0.867 & \\
\hline $\begin{array}{l}\text { KNOSH } \\
\text { ABEHA }\end{array}$ & 0.477 & 0.574 & 0.611 & 0.476 & 0.507 & 0.876 \\
\hline
\end{tabular}

\section{Structural Equation Model analysis (SEM)}

TABLE VI HYPOTHESIS TESTING IN SEM

\begin{tabular}{|c|lcl|c|c|c|}
\hline & & & & Estimate & $\mathrm{P}$ & Resulted \\
\hline 1 & $\begin{array}{l}\text { ALORGB } \\
\text { EN }\end{array}$ & $\rightarrow$ & $\begin{array}{l}\text { KNOWSHA } \\
\text { INT }\end{array}$ & 0.084 & 0.082 & Unsupported \\
\hline 2 & $\begin{array}{l}\text { ALPERB } \\
\text { EN }\end{array}$ & $\rightarrow$ & $\begin{array}{l}\text { KNOWSHA } \\
\text { INT }\end{array}$ & 0.432 & $* * *$ & Supported \\
\hline 3 & $\begin{array}{l}\text { SUBNOR } \\
\text { MS }\end{array}$ & $\rightarrow$ & $\begin{array}{l}\text { KNOWSHA } \\
\text { INT }\end{array}$ & 0.335 & $* * *$ & Supported \\
\hline 4 & $\begin{array}{l}\text { PERCOM } \\
\text { P }\end{array}$ & $\rightarrow$ & $\begin{array}{l}\text { KNOWSHA } \\
\text { INT }\end{array}$ & 0.304 & $* * *$ & Supported \\
\hline 5 & $\begin{array}{l}\text { KNOWS } \\
\text { HAINT }\end{array}$ & $\rightarrow$ & $\begin{array}{l}\text { KNOSHAB } \\
\text { EHA }\end{array}$ & 0.67 & $* * *$ & Supported \\
\hline
\end{tabular}

Note: $* * *$ indicates $\mathrm{p}$-value $<0.01$

As can be seen from the SEM result, except the relationship between altruism organizational benefit has significant value less than 0.05 (0.0082), the rest of paths are significant since its p-value are both less than 0.05.Four hypotheses were also supported

The research results confirmed the positive relation between Altruism personal benefit and knowledge sharing intention $(\beta=0.432 ; \mathrm{p}<0.01)$. Therefore, $\mathrm{H} 2$ is supported in this research model. As further expectation, there is a positive relation between subjective norm and knowledge sharing intention $(\beta=0.335 ; \mathrm{p}<0.01)$ Thus, $\mathrm{H} 3$ is definitely confirmed. The same result was found on the relationship between perceive competence and knowledge sharing intention $(\beta=0.304, p<0.01)$. H4 is also supported. The most expected relationship in this research, between knowledge sharing intention and knowledge sharing intention is extracted the positive result $(\beta=0.67, \mathrm{p}<0.01)$. H5 is supported. However, the first hypothesis is recorded by negative relationship, altruism organizational benefit and knowledge sharing intention $(\beta=0.084$; $\mathrm{p}<0.081)$. So, H1 are not confirmed.

\section{Check for model fit}

Chi-squared /degree of freedom is 3.145 with pvalue $=0.000$. Moreover, order indices also fit well: $\mathrm{CFI}=0.938, \mathrm{GFI}=\mathrm{TLI}=0.949$. All of these indices are greater than 0.9. RMSEA numerator is acceptable fit because this number is less than 0.075 .
Therefore, we can be accepted that the model has an acceptable fit.

\section{DISCUSSIONS AND RECOMMENDATIONS}

With three independent variables: Altruism personal benefit, Subjective norm, and Perceive competence have positive correlations and impacts with knowledge sharing intention. It means that the hypotheses 2, 3, 4 were supported. Moreover, with high further expectation, positive influence is investigated based on knowledge sharing intention and knowledge sharing behavior, the model at the end was proved to include four predictors.

First, this study is one of the first empirical test of the antecedents of employees' knowledge sharing intention and knowledge sharing behavior in technology sector in Ho Chi Minh City in Vietnam. The research approached self-determinant as a main dimension for employees' knowledge sharing. Thus, this contribute to the literature for other researchers, practitioners, and/or technology company. The findings delivered rare evidences about the correlation between knowledge sharing intention and knowledge sharing behavior.

Second, this research found number of factors predicting knowledge sharing intention and knowledge sharing behavior, sorting by strength order as follows: Altruism personal benefit, subjective norm and perceive competence. For altruism for personal Satisfaction, company should apply the format and range the personal incentive as hard reward and soft reward to motivate their employee continue happy with sharing knowledge to coworker and manager. In order to apply Subjective Norms component in reality for improving Knowledge Sharing Intention, manager should continue support \& encourage their employee sharing their knowledge. Moreover, manager should do more in put them in sharing situations. Finally, each items of Perceived Competency are very good to stay strong in this scale. Company and manager have just give them more time and chance to practice and training skill. In specific, communication skill, presentation skill and sharing skill are related with how they are confident in sharing knowledge with more people.

\section{CONCLUSION}

The study has met all research objectives. Firstly, the study confirmed that four factors had significant influence on dependent factor of knowledge sharing behavior. Secondly, key drivers of knowledge sharing behavior and its antecedents have been found through SEM test. Lastly, suggestions should be learnt from final research model and literature that includes: managers, technical company should invest money, time, policies to consider factors of Altruism personal 
Vo Vuong Bach/ International Journal of Business and Management, 2(2) 2018, Pages: 30 -39

benefit, subjective norm and perceive competence in the workplace to better off from employees' sharing behavior. For example, Company and managers have just give them more time and chance to practice and training skill.

The study has some empirical contributions to the field. However, the study met some limitations. Initially, the timing data collection is not long enough. So, the result of this results may incur some chances of bias. Moreover, this study tested the model in the field of technology companies in Ho Chi Minh City, it could not be described for total of Vietnam sampling. Thus, future research should open the scope to other fields and explore the new moderator and mediation variables that make this research model more practical.

\section{REFERENCES}

[1] Yafang Tsai, "Relationship between Organizational Culture, Leadership Behavior and Job Satisfaction," BMC Health Serv Res. 2011; 11: 98, Published online 2011 May 14. doi: 10.1186/1472-6963-11-98

[2] Juan C. Rivera- Vazquez, Lillian V. OrtizFournier, Felix Rogelio Flores, (2009), "Overcoming cultural barriers for innovation and knowledge sharing", Journal of Knowledge Management, Vol. 13 Iss: 5, pp.257 - 270.

[3] Ahmad N, Daghfous A (2010), "Knowledge sharing through inter-organizational knowledge networks challenges and opportunities in the United Arab Emirates", Eur. Bus. Rev., 22(2): 153

[4] Polanyi, Michael (1966), "The tacit dimension", University of Chicago Press: Chicago, 4.

[5] Nonaka, I. (1994) "A dynamic theory of organizational knowledge creation", Organization Science, Vol.5, No.1, February, p. 14.

[6] De Long, D.W. and Fahey, L. (November 2000). Diagnosing cultural barriers to knowledge management, The Academy of Management Executive, 14(4), Briarcliff Manor, pp. 113-127.

[7] C. K. Lee and S. Al-Hawamdeh, "Factors impacting knowledge sharing," J. Inf. \&amp; Knowl. Manag., vol. 1, no. 01, pp. 49-56, 2002.

[8] T. Boon-In, W. Choy-Har, L. Chee-Hoong, O. Keng-Boon, and C.-Y. N. Felix, "Assessing the link between service quality dimensions and knowledge sharing: Student perspective," African J. Bus. Manag., vol. 4, no. 6, pp. 1014-1022, 2010.

[9] Nonaka, I. and Takeuchi, H. (1995). The knowledge creating company. New York, NY: Oxford University Press.

[10] Szulanski, G. (1996), "Exploring internal stickiness: Impediments to the transfer of best practice within the firm." Strategic Management Journal, 17, 27-43.

[11] Cockrell, R.C., \& Stone, D.N. (2010). Industry culture influences pseudo-knowledge sharing: a multiple mediation analysis. Journal of Knowledge Management, 14, 841-857.

[12] Gagne, M., \& Deci, E.L. (2005). Selfdetermination theory and work motivation. Journal of Organizational Behavior, 26(4), 331-362.

[13] Sheldon, K.M., Turban, D.B., Brown, K.G., Barrick, M.R., \& Judge, T.A. (2003). Applying selfdetermination theory to organizational research. Research in Personnel and Human Resources Management, 22, 357-393

[14] Grolnick, W.S., \& Ryan, R.M. (1987). Autonomy in children's learning: An experimental and individual difference investigation. Journal of Personality and Social Psychology, 52(5), 890-898. [15] Ryan, R.M., Lunch, M.F., Vansteenkiste, M., \& Deci, E.L. (2011). Motivation and autonomy in counseling, psychotherapy, and behavior change: A look at theory and practice. The Counseling Psychologist, 39(2), 193-260.

[16] Ryan, R.M., Lunch, M.F., Vansteenkiste, M., \& Deci, E.L. (2011). Motivation and autonomy in counseling, psychotherapy, and behavior change: A look at theory and practice. The Counseling Psychologist, 39(2), 193-260.

[17]Grolnick, W.S., \& Ryan, R.M. (1987). Autonomy in children's learning: An experimental and individual difference investigation. Journal of Personality and Social Psychology, 52(5), 890-898. [18] Mitchell, J.I., Gagne, M., Beaudry, A., \& Dyer, L. (2012). The role of perceived organizational support, distributive justice and motivation in reactions to new information technology. Computers in Human Behaviors, 28, 729-738.

[19] Chiu, C.M., Hsu, M.H., \& Wang, E.T.G. (2006). Understanding knowledge sharing in virtual communities: An integration of social capital and social cognitive theories. Decision Support Systems, 42(3), 1872-1888.

[20] Tsai, M.T., \& Cheng, N.C. (2010). Programmer perceptions of knowledge-sharing behavior under social cognitive theory. Expert Systems with Applications, 37(12), 8479-8485.

[21] Chang, H.H., \& Chuang, S.S. (2011). Social capital and individual motivations on knowledge sharing: Participant involvement as a moderator. Information \& Management, 48(1), 9-18,

[22] Chin, W.W., Thatcher, J.B., \& Wright, R.T. (2012). Assessing common method bias: Problems with the ULMC technique. MIS Quarterly, 36(3), 1003-1020R. Ulrich, The impact of flowers and plants on workplace productivity, Texas A \& M University, 2003.

[23] Hall, H. (2001). Input-friendliness: motivating knowledge sharing across intranets. Journal of Information Science, 27(3), 139-146

[24] Deci, E.L., \& Ryan, R.M. (2000). The "what" and "why" of goal pursuits: Human needs and the self-determination of behavior. Psychological Inquiry, 11(4), 227-268 
Vo Vuong Bach/International Journal of Business and Management, 2(2) 2018, Pages: 30-39

[25] Bock, G., \& Kim, Y. (2002). Breaking the myths of rewards: An exploratory study of attitudes about knowledge sharing. Information Resources Management Journal, 15(2), 14-21

[26] Cruz, N.M., Perez, V.M., \& Cantero, C.T. (2009). The influence of employee motivation on knowledge transfer. Journal of Knowledge Management, 13(6), 478-490

[27] Bock, G.W., Zmud, R.W., Kim, Y.G., \& Lee, J.N. (2005). Behavioral intention formation in knowledge sharing: Examining the roles of extrinsic motivators, social-psychological forces, and organizational climate. MIS Quarterly, 29(1), 87111

[28] Hall, H. (2001). Input-friendliness: motivating knowledge sharing across intranets. Journal of Information Science, 27(3), 139-146

[29] Hall, H., \& Graham, D. (2004). Creation and recreation: motivating collaboration to generate knowledge capital in online communities. International Journal of Information Management, 24(3), 235-246

[30] Lin, H.F. (2007). Effects of extrinsic and intrinsic motivation on employee knowledge sharing intentions. Journal of Information Science, 33(2), 135-149.

[31] A. Srivastava, K. M. Bartol, and E. A. Locke, "Empowering leadership in management teams: Effects on knowledge sharing, efficacy, and performance," Acad. Manag. J., vol. 49, no. 6, pp. 1239-1251, 2006
[32] R. McDermott and C. O'Dell, "Overcoming cultural barriers to sharing knowledge," Journal of Knowledge Management, vol. 5. pp. 76-85, 2001 [33] Bandura, A. (1981). Self-referent thought: A developmental analysis of self-efficacy. In J. H. Flavell \& L. Ross (Eds.), Social cognitive development: Frontiers and possible futures (pp. 200-239). Cambridge: Cambridge University Press. [34] Heckhausen, H., Schmalt, H.-D., Schneider, K. 1985. Achievement Motivation in Perspective. Trans. M. Woodruff, R. Wicklund. New York: Academic. $337 \mathrm{pp}$ across intranets. Journal of Information Science, 27(3), 139-146

[35] Taylor, J., \& Boggiano, A. K. (1987). The effects of task-specific self-schemata on attributions for success and failure. Journal of Research in Personality, 21, 375-388

[36] Iacobucci Churchill And, Dawn Iacobucci, Iacobucci Churchill, Gilbert A. Churchill (2006). Marketing research. Academic Internet Publishers Incorporated

[37] Hair, J.F. Jr., Anderson, R.E., Tatham, R.L., \& Black, W.C. (1998). Multivariate Data Analysis, (5th Edition). Upper Saddle River, NJ: Prentice Hall

[38] Hair, J., Black, W., Babin, B., Anderson, R., \& Tatham, R. (2006). Multivariate data analysis (6th ed.). Uppersaddle River, N.J.: Pearson Prentice Hall

[39] Tull, D. S., Hawkins, I. D. (1993), Marketing research: measurement and method (6ed). New York: Macmillan

[40] Likert, R. (1932). A technique for the measurement of attitudes. Archives of Psychology, 22(140), 1-55

[41] Ghiselli, E. E. (1955). The measurement of occupational aptitude. Berkeley: University of California Press

[42] Guilford, J. P. (1954). Psychometric methods. New York: McGraw Hill 